The enclosed list is not a very long one, but I believe it con. tains a majority of the words which are habitually pronounced wrong by members of the medical profession.

A Medical Studest.

\title{
CIINICAI, IIECTURE ON INFLUENZA.
}

BY W. T. GAIRDNER, M.1), PHYSICLAN TO THE ROYAI. INFIRMARY, AND LECTURER ON CLINICAL. MEDICINF, NDINBURGH.

I INviTe your attention to-day to a subject of great importance, andvery directly suggested, not perhaps by any one case now in the wards, but by a combination of circumstances which you have witnessed during the last fortnight. It is to the prevalence of certain diseases in our hospital wards, which, taken collectively, amount to the proof of an epidemic morbid tendeney; that is to say, which show, by the extent and manner of their diffusion, the existence of a inorbid influence operating temporarily upon the population at large. I cannot, indeed, show you in the wards a single typical case of this epidemic disorder, as it is seen so frequently outside, unless it be that of the woman just admitted into the ferer ward. But, although I camnot place before you the ordinary forms of the epidemic (because these are comnonly too mild to be admitted into hospital), I can show you its accidents and complications in sufficient number to furnish a text for some remarks on its nature and prevalence.

You may recollect that, at the beginning of the month, we had very f'ew acute cases of disease, though there were many interesting chronic cases, chiefly of aldominal affections, and almost all of organic discases. The few acute cases that we had were fevers, and these almost all of one kind, viz., enteric typhus, about which I may have more to say at another time. Now, on the other hand, the wards are crowded with more or less acute cases of disease; and most of these discases are of the chest. Let me enumerate a few of them.

'There is the case of the woman already noticed as having been admitted to the fever ward. She is a healthy-looking young woman, who has becn occupied as a domestic scrvant. She was scized, a few days ago, with shivering, succeeded by headache, pains in the limbs, sickness. Along with these there was a certain amount of catarrh, which has now settled (not very severely, however) upon the chest. The fever is now intense, and very much out of proportion to the severity of the catarrh. Headache persists, the skin is loot, the tonguc loaded, the color dingy, and the general aspect of the patient certainly goes far to justify her being sent to a fever ward. Nevertheless, I believe it will turn out not to be a case of fever, in the ordinary acceptation of the 
term; but of the current epidemic-which I will take the liberty of calling, if' it has not alrearly been called-Influenza.

Had this been the first case of influenza presented to my notice, it might have passed for one of continued ferer or typhus. But eren then I should have remarked its singularly abrupt invasion, the great amount of prostration in this early stage, the extreme sererity of the headache and articular pains, as being rather out of character in any ferer to which we have lately been accustomed. Knowing what I do of other cases, I have no doult these symptoms are owing to influenza. The only question is, whether this woman may have inflenza and fever combined. This question must remain open for the present.

Now, by considering this a case of catarrhal ferer, or of feverish cold (if you like to call it so), in relation with the other facts to which I shall allude presently, you will draw for yourselves the picture of the cpidemic, as we have it.

The first indication we had of anything out of the usual course was, perhaps, that downward tendency of several of our cases of philisis, which, you will recollect, I remarked to you more than a fortnight ago. It does not always happen that cases of phthisis are the first to show a tendency to influenza, and, in this instance, it may have been a coineidenec; but it is a curious coincidence, that, when we had picked out four eases of phthisis as fit suljects for trying the new remedies-the hypophosphites of lime and sodaand had noted them carefinlly for that olject, three out of the four should have been seized with acute symptoms, within a short period of our commeneing the novel treatment. I told you at the time, that I had no reason to blame the remedy for this result, and that it was probably a mere coincidence; I am now disposed to believe that it was one of the first manifestations of the morbid influence of which we have since seen so much.

LTwo of these patients have since died; one went out relicred; another survives, considerably enfecbled, but without acute symptoms.]

On the 11th of November, we saw together a case in the female general ward, of very old-standing chest discase, apparently emplyysema of the lungs, in which acute symptoms had supervened, and the patient appeared to be in extreme danger from respiratory oppression, with fererishness and bronchitis. Under a rery simple treatment, this woman is now improving; lut her case is, no doubt, one of the epidemic in a delilitated sulject.

Shortly before this case was admitted, a boy was brought to the waiting-room screaning with pain, which he referred to his left side. He was also very feverish. He had not mueh catary, but auscultation left us in no doult that there was a degree of dry pleurisy on the left side, and also a friction sound, not so well marked, over the pericardium. Under moderate lecching and opi- 
ates, he was soon convalescent; but the respiratory friction sound continued loud and characteristic, and we have detained him in the ward mainly for your bencfit. I had some doubts, at first, whether this boy had not suffered perforation of the lung; but it was not so. I do not say it was a woll-marked case of influenza, but I mention it by the way.

The next case was that of a boy from the Industrial School, who had gone through a distinct attack of feverish catarrh liefore we saw him. The traces remaincd in the form of bronchitis of the smaller tubes, or rather, l suspect, a tubercular condition of the lung, with bronchitic signs. This boy has probably had an unsound chest for some time. He is better, however; inded, nearly well.

About this time, I thouglat it right to pay a visit to the Industrial School, as I had scen several cases of feverish disorders from thence, which the head-master sent up for my inspection. I found thirteen or fourteen boys smartly ill with cold of the head or chest, and scveral of them plainly very feverish. Coughs resounded on every side; and squill mixture, with paregoric and ipecacuanha, were greatly in demand. None of the cases were, howerer, dangerous.

On Norember 14th, I directed your attention to a very acute case of bronclitis, or broncho-pneumonia, adınitted two days be. fore. The ferer was very intense on admission, but had quite sub. sided, before you saw the patient, under the treatment by conside. rable doses of tartar emetic, employed by Dr. Yellowlecs from the commencement. The paticnt, a young girl of seemingly sound constitution, recovered rapidly - the large doses of tartar emetic being replaced by a simple cough mixture, with small doses of antimonial wine, after the lapse of about 48 hours; as soon, indeed, as the fever showed signs of retreating. No other medicine was required in this case.

Very different was the result of treatment, or rather of the neglect of treatment, in another case in the same ward. A young woman, the mother of a family, was seized with acute bronehitis, and lay many days neglected. She was then seen by Dr. Watson, who, after blistering the chest and administering some internal remedies, sent her into the hospital. In this case, seen by us only at an advanced stage, the fever had assumed a hectic character. Occasional flushes overspread the face; there was marked dyspnoea and lividity; sweating was very severe every night, and sometimes in the day; and prostration very considerable. She has since had acidulous drinks, antispasmodics and opiates, and is bet. ter; but her convalescence is very slow, fever is not subdued, and I greatly fear that the seeds of tubercular diseaso have been laid in this case. She flushes whenever she is spoken to, and is very nervous. [This patient was lately dismissed, as she felt it neces- 
sary to go home to her family; but she is very unfit for houschold duties, and will probably be so for some time.]

Two other cases of chronic catarrh, with acute exacerbation, were admitted into the male ward, and were seen by you on November 18th. Both of these were strect-porters, and men above 60 years of age-lby no means temperate in their habits. I will not, however, dwell upon thein.

The same day, November 18 th, brought under your notice, for the first time, two extremely interesting cases of acute disease, having the imprint of the cpidemic tendency.

One of these was a case of acute pucumonia, or pleuro-pneumonia, in a previously healthy man of 28 years of age. The discase had run a course of many days previous to admission, having begun in symptoms altogether like simple influcnza, succeeded, at the end of a week, by pain in the right side of the chest and difficulty of breathing, with shivering fits. We found the whole lower lobe on the right side more or less consolidated, the sputum rusty, and the fever considerable. The night of admission, before treatment had been well begun, pain occurred on the opposite (left) side, at the lower part; and this aggravation was attended with a pulse of nearly 140 in the minute, at one period, and with respirations between 50 and 60 in the minute. So soon, however, as the tartar emetic began to take effect, these symptoms subsicled; and next day we noted the pulse at 78 , and the respirations at 32 , the skin cool and moist, and the general state quite satisfactory; though a certain amount of dull percussion, with some consonatingr râle, existed at the lower part of the left lung, and the physical signs on the right side were unchanged. In another day, the line of dull percussion in the right lateral region was lower by an inch and three quarters, and from this period the convalescence may be said to have begun. The operation of the grain-doses of tartar emetic here was most prompt and satisfactory; and, as the fever and dyspnœa have entirely subsided, the pulse being 72 and the respirations 26 in the minute, I am of opinion that we may now suspend the remedy, and leave the cure to be completed by nature. [The convalescence was uninterrupted. The patient left on $2 \mathrm{~d}$ December, perfectly well.]

The other case which we saw for the first time on the 18tl, was that of a woman in the fever ward. 'This patient, a domestic servant, aged 28, of rather corpulent habit, always enjoyed good health till a fortnight ago. At.that time she was seized with pains in the head, back, and limbs, with a fecling of lassitude and exhaustion, which confincd her to bed for three or four days; but at the end of that time she was somewhat better, and tried to resume her ordinary work-to very little purpose, as in a day or two more she took to bed again, and has been feverish ever since.

I believe that this case is one of enteric typluse, or typhoid fe. 
ver as it is often called. I make this diagnosis, howerer, chiefly on the ground that certain rose-colored spots, which you saw me mark on the skin yesterday, bear a strong resemblanee to the characteristic cruption of that ferer. Should these spots continue to appear, we shall feel sure of our diagnosis; although there is at present not a trace of abdominal complication, and all the more prominent symploms are thoracic, so that there is little doubt the epidemic tendency is showing itself strongly in this woman. There are, in fact, the following rery formidable symptoms:-great acceleration of the respiration; dingy lividity of countenance, with flushed cheeks; small and very frequent pulse; considerable pain in the chest, not localized; some delirium; and I have little doubt that some peculiar form of broncho pnemonia is present, as there is a scanty sputum, deeply tinged with purple blood, and we find, on cxamination, limited dulness on percussion, together with consonating respiration and râle in both lacks, at the lower part of the lungs. It is easy to see in this case enteric ferer, complicated with influenza, and with very serions, though ill-defined, acute disease of the lungs-a very ominous conjunction, and all the more so as the debility of the patient forbids the employment of active remedies, and we must confine the treatment to regulated stimulation. I must say, that the state of this woman appears to me perilous in the extreme.

[The sequel of this case justified our fears. On the 21 st she was visited, on account of my unavoidable absence from town, by Dr. IV. Beglie, who inarked out additional rose-spots, thus removing all doubt as to the diagnosis. The chest symptoms, however, still predominated; there had only been one stool, and that a natural one, since admission; and there was no pain or tenderness of the aloclomen to any appreciable extent. On the night of the 21 st a very loose stool was passed, containing blood. Another followed next day, and another the suceeding night, the blood being in large quantity, notwithstanding the application of icc to the aldomen, and the administration of acetate of lead, with opium, internally. On the $23 \mathrm{~d}$, at visit, she was manifestly sinking. She had been very restless and delirious, and had three other stools, largely composed of blood. The tongue was dry and brown, and the pulse almost imperceptible. There was no additional embarrassincut of breathing, and I did not cxamine the back; but over the right front there was marked duhness on percussion, with feeble tubular respiration and consonating râle. She died on the morning of the 24 th.

Post-mortem examination showed numerous enlarged and congested patchos of Peyer in the ileum, in a state of ulceration and sloughing; with enlarged, congested and softened mesenteric glands. The lungs were in an extremely curious and almost indescribable condition; the right lung almost entirely devoid of 
air, flaccid, evidently collapsed, but showing throughout, on section, much congestion, and here and there patches of hamorrhagic condensation; the bronchi loaded with mucus decply stained with blood. In the left lung there was a good deal of collapse at the base and root; but, on the whole, not much disease. In neither lung was there anything like ordinary hepatization, and the pleuræ were quite smooth, and free from exudation. The spleen, as usual, was large and soft.

It is worth noticing, that the nurse of the ward, a most carcfin and attentive person, was under the impression that this patient was menstruating two or three days before death, and that the patient hersclf had a similar impression. The examination of the uterus and ovaries showed that this impression was erroneous. The nucous membrane was pale throughout; a gelatinous mass of mucus oceupied the cervix uteri, and there was no recent corpus luteum. It is evident that the stains of blood from the bowels had led to a mistake in this particular.]

The only other casc worth mentioning in illustration of the epidemic tendency, is that of a little girl, admitted on the 19 th, as she has been screral times before, on account of discase of the heart. She has, I think, a contracted mitral orifice; and with this there is associated, at present, a great deal of lividity, with feverishness, and marked prostration of strength; the consequences, no doubt, of influenza acting upon organs predisposed to diseasc. I should think badly of this case if I had not seen it before; but this girl has repeatedly got orer attacks considerably worse than the present in a very short time. She has all that clasticity of constitution which appears to be the exclusive endowment of youth; and she is in every respect a very good and hopeful little patient. [She recovered in a few days.]

Let me now review these facts. Here, within the space of less than a fortnight, you have seen admitted into our wards (with an average population under 40) no fewer than 11 cases of febrile disease, associated with pulmonaly symptoms of one kind or other. Most of these, no doubt, were complicated cases, and only one of them could be called simple influenza. But this is because simple influenza is usually too rapid and too mild a discase to be adnitted to an hospital. We sce here, not the disease, but the consequences and complications of the disease. In private and in dispensary practice we see the disease itsclf.

[Of these 11 cases of cliest affection,

1 was double pleuro-pneumonia;

1 was pleurisy and pericarditis;

2 were very acute bronchitis, or broncho-pncumonia, in one with a probalsle tubercular complication;

1 was sul)-acute bronchitis, certainly with tubercular ante. cedents; 
3 were sub-acute bronchitis, superrening on old emplysema of the lungs;

1 was sub-acute bronchitis, supervening upon old valrular disease of the heart;

1 was enteric typhus, with very acute pulmonary complication; and

1 was influenza, pure and simple.]

While we have been watching these cases together, I have scen many, and heard of many more, cases of the simple and ordinary form of the discase. Not a few of yourselves have had it, and two or three have been seriously ill. Most of the eases that I have seen, however, have been remarkable for the sharpness and suddenness of the attack, and not less so for the rapidity of the passage from a state of feverish prostration to convalescence. I have found a man with a pulse of 130 at night, and next day he las been up and about. This, of course, only happens with sound constitutions. In one or two instances, it has appeared to me that an emetic, giren in time, has anticipated or cut short the attack. Certainly it has been followed by great relief. For the rest, the bed, or, in mild cases, the sofa, restricted dict, laxatives where required, and liberal doses of opium where there is much restlessness and exhaustion, seem to me to comprise all the necessary treatment of ordinary cases of influenza, even when severe. In the complicated cases no rule can be laid down. Some are very amenable to rumedies, others run their course in spite of treatment. You have secu illustrations of both kinds in these wards.Edinburgh Medical Journal, January, 1858.

['To be continued.]

\section{Reports of Jerteal Socictirs.}

KXTRACTS FROM THE RECONDS OF TIIE BOSTON SOCIETY YOR MEDICAL, IMPROVFMENT. BY F. E. OJIVER, M.D., SBCRETARY.

DEc. 14th.-Large Encephaloid Tumor arising from the inside of the Stomach. Symploms comparatively mild. -The specimen, with the following history of the case, was sent by Dr. F. S. Ainsworri, and exhibited by Dr. JACKsON.

Mr. S., aged 55, was born and lived in Paris, France, until the last ten years; he was a stove-maker by trade, and of regular habits; temperament bilious; of full habit, and even inclined to corpulency. In 1836, he began to be troubled with a sense of oppression whenever food or drink was taken into the stomach, occasionally amounting to a severe pain. This usually lasted two or threc hours during the entire course of his disease. Never experienced any sickness at the stomach, and never vomited. Bowels costive, and he suffered severely from hemorrhoids. Skin pale, but without any yellow or straw-colored tinge. $\Lambda$ bout the month of June last, the gastric symptoms became more severe. There was more pain after eating; the diluted wine or 